\title{
LANGUAGE CHANGE AND DEVELOPMENT: HISTORICAL LINGUISTICS
}

\author{
Trisna Dinillah Harya \\ STAIN Jurai Siwo Metro Lampung \\ Email: trisnaharya@yahoo.com
}

\begin{abstract}
:
Language can change and develop by itself slowly. Language can change and development because of adaptation of development and pattern change and system of society life, such as level of education, social, culture and technology mastery. Language change and development can occur internally and externally. In this article the changes internally and language development will be reviewed by looking through the study of his torical change and development language based on the history of its development. While changes in external and development will be explored through the study of Sociolinguistics by examining and looking at changes and developments that language is influenced by socio-cultural factors that occur in society. Changes internally initially occurred in the behavior of speakers in their everyday lives to adjust to each other, and followed by a tendency to innovate in groups of people who are already familiar, then followed by other changes in sequence, which ultimately makes a language different each other, although originally derived from a single language family. Changes in the external language change and language development is caused by the contact of a language with other languages, where humans as social beings who have been cultured either interconnected or inter-ethnic nations in the world in a country.
\end{abstract}

Key words: Language Changes, Internal Change, External Change, Historical linguistics

\section{INTRODUCTION}

Language change as a concept and as a subject of linguistic investigation is often regarded as something separate from the study of language in general. Recent research into the topic, however, has strived to highlight the continual nature of change and to emphasize that the synchronic and diachronic views of change can be unified, providing a panchronic perspective in which the relevance of small changes observed in the present can be shown to hold for larger scale changes in the past.

Furthermore, research in the last three or four decades has been concerned with understanding the precise mechanisms of change just as much as with providing linguistically acceptable accounts of attested changes. The field is served well by literature. There are journals which are specifically dedicated to language change, such as Diachronica, or to certain aspects of this, such as the Journal of Historical Pragmatics. In addition, other journals strongly favour analyses that illuminate language change, frequently from a certain perspective, such as Language Variation and Change. 
There are many textbooks that deal with language change (Aitchison 2001, McMahon 1994, Bauer 1994), frequently under the heading of historical linguistics. From the English speaking world one could quote Bynon (1977), Milroy (1992), Trask (1996), Campbell (1998), Fennell (2001), Crowley (1998) as representative examples. Some of these deal with the three main views of change which had been proposed by the middle of the 20th century, namely the Neogrammarian model from historical linguistics in the 19th century (see the discussion in Labov 1981), the structuralist approach, initiated by de Saussure at the beginning of the 20th century and the generative approach, which while beginning in the 1950 's as a purely synchronic approach to language description with the work of Noam Chomsky, came in the following decade to be applied to issues in language change, see King (1969).

As generative grammar has undergone many revisions, the analyses of language change stemming from the standard theory of the mid-1960's have been left aside and more subtle and discriminating approaches have been developed. In particular, deficient analyses, which derive from the model used at the time, have been abandoned. For instance, the scholarly concern of the late 1970's with rule-ordering, particularly in phonology (see Kenstowicz and Kisseberth 1979 and Koutsoudas 1976), is now seen to result not so much from the data examined but from a non-linear, unstratified view of phonology, something which was remedied with the advent of lexical phonology and the various forms of syllablebased phonology.

A language is a social fact, a kind of social contract. It exists not in an individual, but in a community (Bauer,2007,p.3). A language is a system of conventional vocal signs by means of which human beings communicate. This definition has several important terms, each of which is examined in some detail in the following sections. Those terms are system, signs, vocal, conventional, human, and communicate (Algeo, 2010,p.2).

According to Saussure (1959,p.9) language is not to be confused with human speech [langage], of which it is only a definite part, though certainly an essential one. It is both a social product of the faculty of speech and a collection of necessary conventions that have been adopted by a social body to permit individuals to exercise that faculty. Taken as a whole, speech is many-sided and heterogeneous; straddling several areas simultaneouslyphysical, physiological, and psychological-it belongs both to the individual and to society; we cannot put it into any category of human facts, for we cannot discover its unity. 
Brown (2007,p.6), definitions of language fields the following composite definition:

1. Language is systemic

2. Language is a set of arbitrary symbols

3. Those symbols are primarily vocal, but may also be visual

4. The symbols have conventionalized meanings to which they refer.

5. Language is used for communication.

6. Language operates in a speech community or culture.

7. Language is essentially human, although possibly not limited to humans.

8. Language is acquired by all people in much the same way, language and learning both have universal characteristics.

Language is part of linguistic field. Linguistics deals with human language. Human language is just one way in which people communicate with each other, or gather information around them. Many linguists have made contributions to this wider field. Campbell (2002,p.1) says that early developments in linguistics were considered part of philosophy, rhetoric, logic, psychology, biology, pedagogy, poetics, and religion, making it difficult to separate the history of linguistics from intellectual history in general, and, as a consequence, work in the history of linguistics has contributed also to the general history of ideas. Still, scholars have often interpreted the past based on modern linguistic thought, distorting how matters were seen in their own time. It is not possible to underst and developments in linguistics without taking into account their historical and cultural contexts.

Typical dictionary definition of linguistics is something like =thescience of language‘. A rather looser definition, such as _linguistics is the study of all the phenomena involved with language: its structure, its use and the implications of these', might be more helpful, even if it seems vaguer (Bauer, 2007,p.11).

Language change and development national, international or ethnic language cannot be avoided. They are caused by acculturation of culture. This case can be caused by speaker moves to other places. If someone or speaker moves to new place, the speaker will influence of new society, so there are new dialect, find of the new word, even syntactic structure language also change. Language can change and develop by itself slowly.Language can change and development because of adaptation of development and pattern change and system of society life, such as level of education, social, culture and technology mastery.

The process of language change is influenced by many factors. In this paper the writer divides into two factors. They are internal change and external change. Internal change refers 
to grammatical, while external change is caused by other languages. It can fast process and usually it begins from lexicon and other language elements.

In this paper the writer will explain about change and development of language historically in two languages that have same language family even they from same branch. They are German and English. Change that happens in their language is structurally and format word. In external change the writer will relates to the entity of language in other language space in multilingual society. Language can be separated from sociolinguistic.

The definition of sociolinguistic is combination of two words. They are sociology and linguistic. Thus, sociolinguistic is from two sciences discipline; sociology and linguistic. Language and society have close relation. Language is as social product with many functions in order to be used maximal by human being in communication and interaction with each others.

In sociolinguistic, language is not only viewed as language but it can become communication, interaction and use in kinds of moments in human being living in society. In society, one is not only as individual who separate with other but member of society. Language is not only personality using but using in social activities. Everyone has different in using of language, phonetic, phonemic, and choosing of word, idiolect and structure of sentences. In fact, there are of dialect in society. The difference of dialect of language is caused by speaker's different class, region, social status, and speaker habitual. Sociolinguistic is discuss about relation between language and speaker in society. Sociolinguistic also describe about system of social status in using language and research of dialect in multilingual society in language change and development.

\section{DISCUSSION}

\section{The Nature of Language Change}

Raymond (2003,p.2) says that Any treatment of linguistics must address the question of language change. The way languages change offers insights into the nature of language itself. The possible answers to why languages change tell us about the way language is used in society, about how it is acquired by individuals and may reveal to us information about its internal organization. There is no simple explanation for why languages change. This is an area in which there is much speculation and little proof. The area is an interesting and fruitful one but there are few if any direct answers. 
For this reason historical linguistics has traditionally been concerned with how languages evolve and not why they do so in one particular direction and not in another. To begin this section a number of statements about language change are be made. 1) All languages change There is no such thing as a language which is not changing. The rate of change may vary considerably due to both internal and external factors. English, for example, has changed greatly since Old English. Other languages, like Finnish and Icelandic, have changed little over the centuries. 2) Language change is largely regular One can recognise regularities in the types of change which languages undergo, even if these cannot be predicted. (Raymond, 2003,p.2).

\section{Historical Linguistic}

Many histories of linguistics have been written since the 1970s. Works on the history of nationalism is in various countries or focusing on a particular topic or subfield, for example on the history of phonetics. The history of linguistics has had to deal with the vastness of the subject matter. Branch of linguistic is phonology, morphology, syntax and semantic. Phonology also deals with speech sounds, but at a rather more abstract level. While phonetics deals with individual speech sounds, phonology deals with the systemswhich incorporate the sounds. It also considers the structures the sounds can enterinto (for example, syllables and intonational phrases), and the generalizations thatcan be made about sound structures in individual languages or across languages.

Morphology deals with the internal structure of words - not with their structure in terms of the sounds that make them up, but their structure where form and meaningseem inextricably entwined. So the word cover is morphologically simple, and itsonly structure is phonological, while lover contains the smaller element love and some extra meaning which is related to the final $\langle r\rangle$ in the spelling. Another way of talking about this is to say that morphology deals with words and their meaningful parts. (Bauer, 2007,p.12).Syntax is the part of a language system or description concerned with arranging words within constructions, distinguished from morphology (Algeo,2010,p.297).

In other definition, Bauer, (2007 ,p.12-13) says that Semantic deals with the meaning of language. This is divided into two parts, lexical semantics, which is concerned with the relationships between words, and sentence semantic which is concerned with the way in which the meanings of sentences can be built up from the meanings of their constituent words. Sentence semantics often makes use of the tools and notions developed by 
philosophers; for example, logical notation and notions of implication and denotation. History of linguistic theory will discuss below:

1. Traditional linguistic.

The expert of traditional linguistic is Plato and Aristotle. Traditional linguistic analyze language based on philosophy and semantic. In traditional linguistic is not known the differences of speaking and writing language. The language is arranged in the other language, especially latin. The problem of language is described by logical. Below is history of traditional linguistic:

\section{1) Greek period}

Traditional linguistic had been known in Greek period, it is about 5th BCuntil 2nd century. There was debate among linguists;

a) Natural and conventional language. Naturalist argued that every word has relation to thing, while conventionalist argued that language is conventionally; it means the meaning of word is obtained from tradition result and habitual. It may be change.

b) Analogy and anomaly. Plato and Aristotle are Analogist. They said that language is regular. So, people can manage of grammar, but anomalism has argument that language is irregular, for example child is not childs but children, etc

2) Roman Period

Study of language in Roman period is continuation of Greek period. In this period Varro (116-27BC) wrote De Lingua Latina and Priscia had Institutiones Grammaticae.

3) Middle age

In this period, in Europe has concern of language study, especially scholastic philosopher. Latin language became lingua Franta, because it was as church, diplomatic and science language.

4) Renaissance

Many scholars were mastering of Latin, Greece, Hebrew and Arabic. They are also arranged of grammar and made comparison.

5) Pre - Modern Linguistic.

In this period has important history; there is relation of Sanskrit to Greek, Latin and other German language. 
2. Structural linguistic.

In critical theory, structuralism is a theoretical paradigm positing that elements of human culture must be understood in terms of their relationship to a larger, overarching system or structure. It works to uncover the structures that underlie all the things that humans do, think, perceive, and feel. Alternately, as summarized by philosopher Simon Blackburn, Structuralism is "the belief that phenomena of human life are not intelligible except through their interrelations. These relations constitute a structure, and behind local variations in the surface phenomena there are constant laws of abstract culture.

Ferdinand de Saussure (1857-1913), master of structural linguistic. He wrote Course de linguistique Genarale book. The concept of the book is below:

a. Diachronic language

Diachronic literally means, - History calling. It has five main concerns:

- to describe and account for observed changes in particular languages;

-to reconstruct the pre-history of languages and determine their relatedness, grouping them into language families

-to develop general theories about how and why language changes;

-to describe the history of speech communities;

- to study the history of words.

b. Synchronic

Synchronic study of language is to learn a language at a certain period of time only.

While the diachronic study of language is the study of the language of all time, or long time that language is used by speakers.

c. La Langue and La Parole

The last Saussurean idea to be considered is the distinction between parole or speech and langue or language. Speech is the way people actually talk, as it proceeds in the interaction order. Langue is an idealized or formalized version of the way people actually talk, with standardized semantics, idealized syntax and a purified set of linguistic rules. -Languagell is a simplified and academically more approachable version of speech. In this respect it has some resemblances with Weber's ideal types, which tried to get at the underlying meaning and tendencies of historical realities. On the face of it, it would appear that inner speech exists only in the form of speech and cannot be rendered into the form of -language.\|Everyone speaks a something smoothed over and idealized. And inner speech is too wispy and vague to even be identified clearly as a parole much less as a langue (Wiley, 2006,p.13). Historical linguistics studies how languages change or maintain their structure 
during the course of time. While descriptive linguistics investigates and attributes to the linguistic data a uniform status of linguistic simultaneity without any regard for time factor.

\section{Language change and development}

There are two factors in language change; they are internal and external factor. These factors are different in themselves For example, internal factors have very often to do with the establishment of morphological regularity, External factors have primarily to do with the symbolic role of language in society. The levels of language first affected are usually phonetics and phonology, though others may be later embraced by change. They will explain below:

1. Internal language change

Changes internally occurred in the behavior of speakers in their everyday lives to adjust to each other, and followed by a tendency to innovate in groups of people who are already familiar, then followed by other changes in sequence, which ultimately makes a language different each other, although originally derived from a single language family. Internal language change relates to the language change its self. It correlates with grammatical system. it exists in phonology system, phrase sequences and sentence.

To investigate further about language change and development internally the writer will explore of English and German language change and development in some periods as follows: The evolution of English language occurs in fifteen centuries continually in English. The change is occur in three period English language that precise tool to separate of linguistic changing. The period is Old English, middle English, and modern English. In old English has many manners or style of language.

There are four dialect, Northumbrian, Mercian, West Saxon, and Kenntish. Basically the difference between old English and modern English is spelling, pronounce, vocal, and structure. Middle English is in the middle 1150 - 1500. In this period, many of important changing in English language, it is extensive and fundamental changing. At the moment this changing influence of grammar and vocabulary. In modern English occur in 19th century. Changing pronouns to other form there are tree difference, there are not thou, thy, and thee. Ye is changed you; and its as possessive from it. from some English language development pronoun is interesting one. neuter pronoun in old English is hit, his, him, hit. There is a combine of Dative and Accusative.History of German (Germanic) language change and development, concludes of Germanic language family. It began of relation with Rumanian in the first century.Then, different dialect in Germanik . Consonant 
changing build the new dialect in German language (High German). In early period ( old period) the best language exist in dialect collection.

The Document indicated there was struggle of dominance in German. This phenomenon had success to made Latin translation draft and process it. Inthis period borrowing and absorb of latin language, e.g: predigan (modern: predigen)is from Latin, predicare, tempal (modern: temple) comes from Latin templum, spiagal(mirror) (modern:Spiegel) from Latin language speculum.In the middle period, it was about 10501350: some developments in languagechange as follow:

- Consonant change without end sound b,d,g.

- The reduction of vocal without of emphasize syllable /a/ it spell /e/;

- Plural of - day — in old German as normative and exclusive : Taga, genitiv: Tago, dative: Tagun. In middle German became Tage, Tage, Tagen and in modern became (Tag, Tage, Tagen). The big change geographically occurred in (+1350-1650). German dialect was used by office employee, Saxon and government people. It became standart of modern German language.

Modern Period: 1650 - now, the famous development is increasing of German language standard. There is a classification gender of Noun, (1) masculine: der Man(the man), (2) feminine : die Frau (the women), and (3) neutral: das Kind (the child). Explanation above indicates change and development of German and English language in vocabulary, phoneme and structure. It shows that there are change and development of language family background. It can change of speaker sociolinguistic behavior in current region.

2. External language change

External language change and development will be explored through the study of sociolinguistics by examining and looking at changes and developments that language is influenced by socio-cultural factors that occur in society. Changes in the external language change and language development is caused by the contact of a language with other languages, where humans as social beings who have been cultured either interconnected or inter-ethnic nations in the world in a country. They have many purposes in interaction and activities, for example economy, politic, religion, science, acculturation of culture, technology and etc. the language as communication tool in many activities. In Islamic come in Indonesia, many words was borrowed from Arabic, e.g musyawarah, sahih, ikhtiar and etc. The impact of external language change can combine two word in difference language.e.g Madura and Java. The phenomenon of language change and development 
emphasize of sociolinguistic. It is study of relation of language user in social contact and social phenomena in society. Language change can be influenced by many factors. There are economy, politic, culture, geography, and social phenomena. Some one who moves to other place, he or she will bring her/his language in new place. It can influence language change.

Another example of external change is the development colloquially of synthetic forms of auxiliary verbs, particularly in American English. Phonetic reduction leads to a fusion of to with a preceding verb form as in going to $\rightarrow$ gonna or want to $\rightarrow$ wanna. Whether this will ever be accepted in more standard varieties of English depends ultimately on language attitudes and the readiness to accept vernacular forms. Social reasons can be given for why change appears to be more common in some areas of language. For instance, swear words have a high turnover because they lose their force for speakers when they are used and hence the need for new and more forceful terms arises constantly.

\section{Change and levels of language}

Language change offers evidence for the autonomy, but interconnection, of linguistic levels. While there is general consensus on the organization of language as an arrangement of subsystems, there is equal insistence on the fact that these subsystems have definite points of connection. Although the sound and meaning systems of a language are separate there are definite links between the two, for instance, if there is phonological attrition in a language then this may well lead to the opacity of lexical forms which in turn can lead to later reinterpretation as with the many instances of folk etymology.

Before looking at the individual levels of language it is important to point out that in recent research linguists have stressed the gradience of grammatical categories. In English, for example, there is a common practice of using nouns in attributive adjective position which leads functionally to a change in class, e.g. with fun as in A fun party. This is still within a single level of language, that of syntax, but it does show that there is a degree of fluidity among categories, something which is long established in English and is perhaps characteristic of analytical languages as a whole.

\section{a. Phonological change}

On a purely phonetic level one could say that sound change has to do with an increase or decrease in sonority. Segments are usually strengthened in syllable-initial position and weakened in medial and final positions. It is one of the great merits of non-linear phonology to have offered a formal framework for describing these types of change, that is developments which are dependent on syllable structure and syllable position. 
The natural tendency to increase the sonority in medial and final syllable positions has led in many languages, for example in the Indo-European daughter languages, to a loss of inherited inflections which over several centuries has in many cases led to a typological realignment of the individual languages, e.g. with the Romance languages vis-à-vis Latin or English vis-à-vis the Germanic parent language. Grammatical reorganisation due to phonological change illustrates quite clearly the interface between the sound and grammatical levels of language. Another common phonetic development is the exploitation of phonetic polarisations. For instance, if glides become absorbed into preceding consonants, then the effect can be palatalisation (with later reactive velarisation) as in Q-Celtic and Slavic, to mention only two of the more well-known cases.

A similar fictionalization of polarization can be seen in the development of emphatic consonants in Arabic. Phonetic changes of the type described are gradual: but the ultimate effect is to lead to a reanalysis of the exponence of grammatical categories in a language. Two exceptions to gradual phonetic change are epenthesis and metathesis, the introduction of vowels/consonants in specific clusters and the change in the linear order of segments in a word respectively.

However, neither of these processes appears to have attained a grammatical function in a language. The reason may well be that a language either has epenthesis and/or metathesis or it does not. But for grammaticalisation to occur there must be the option of contrast in a language and this would seem to be precluded with the two processes just mentioned.

\section{b. Morphological change}

For many languages morphology is the mediator between deep syntactic case and surface realization. It is obvious that there is no language without syntax and pho nology but there are languages with little morphology (prototypically analytical languages). This fact might seem to suggest that morphology is not part of universal grammar, at least that it can remain unrealized. Surface morphology can be seen as the result of performance phenomena such as phonetic attrition, leading in the fullness of time to cliticisation and grammaticalisation. It is identified as a level of language as it is manifest on the surface and indeed there is a sense in which, in those languages with morphology, that it is a level which can be given a ranking above phonetics. Although the ultimate status of morphology can be debated (because it is not necessary for human language), it is nonetheless a reality for all language types apart from analytical languages.

In the historical development of languages it is probably true to say that morphology has always arisen through the contraction of independent elements. For instance, suffixal 
inflections can be seen to arise where, in a word dyad, one element is a lexical stem and the other a form word. The latter can go through a process of semantic bleaching and cliticisation (attachment to the stem) and ultimately become an inflection, i.e. lose its independent phonetic form and no longer be detachable from the stem.

Once a language has developed a morphology certain forces become dominant which involve specific pathways of change. Nowhere is the operation of internal factors more in evidence than with morphology. This probably has to do with the fact that morphology leads to the organization of words into sets of forms and that for speakers, particularly for language learners, regularity within such sets is highly valued. Irregularity may arise for a variety of reasons, for instance due to suppletion, the mixture of elements from two or more sets within a single paradigm. Internal irregularity within a single paradigm may arise due to certain phonological factors.

A good example of this is the voicing of segments where the immediately preceding syllable does not carry stress, e.g. executive [qg/zekju:tiv] versus execute [/eksikju:t] in present-day English, which in the Indo-European context is known as Verner's Law (Trask, 1996,p.226f.). This together with the shift of /s/ to /r/ (rhotacism) led to considerable irregularity within nominal and verbal paradigms in Germanic. At a later stage analogy (Trask, 1996,p. 105-15), the spread of a dominant pattern to an entire paradigm — the internal factor in language change par excellence — came to bear (Lahiri ed. 2000). Hence in English one finds a sibilant in the verb lose whereas in German $/ r /$ is found throughout the corresponding verb, verlieren.

In Dutch one has the infinitive verliezen (with a sibilant) 'to lose' but the simple past has an /r/: verloor 'lost'. Morphology is rarely involved in externally motivated change. The reason probably is that the latter is driven by social factors, and is dependent on speakers making choices, on inherent variability. This is the case with the phonology of a language: to put it in simple terms one can pronounce sounds/words in different ways and so give social significance to this variation. Equally in syntax one usually has a number of constructions which are roughly equal in semantics terms and so again one has choice. But the system of morphology is much more rigid. However, in those cases where there is variation, for instance in verbal tense marking or conjugation in English (Ihalainen 1994), then this variation can become relevant for language change, frequently leading to the differentiation of varieties of a language. 


\section{c. Syntactic change}

In an overview chapter such as the present one it is impossible to do justice to the vast theme of syntactic change (Roberts, 1993; Harris and Campbell, 1995; Kemenade and Vincent (eds), 1997; Pintzuk, Tsoulas and Warner (eds) 2001). All that one can do in the current context is to point out some general features of the phenomenon and advise readers to consult the relevant literature for detailed discussion of instances and interpretations of syntactic change. It should also be mentioned that syntactic change tends to be the domain of linguists with a more formal orientation. Functional views of language change are often associated with a sociolinguistic or typological approach to the field (see the discussion in Newmeyer 1998, 2002). There is an essential difference between phonological and syntactic change in that syntactic variables do not occur as frequently as phonological ones. Syntactic variation is more likely to be conditioned by internal linguistic factors or depend on questions of style and context rather than external social factors since syntactic structures are repeated less often than phonological ones and are thus less available for social assessment.

Furthermore, syntactic factors are less 'visible' as the structures which they engender are more abstract and hence speakers are less conscious of them. Syntactic structures do not usually have a social identification function like phonological factors as there may well be stretches of speech in which a given syntactic variable does not occur at all and hence does not offer a speaker a clue as to the linguistic affiliation of an interlocutor

\section{CONCLUSION}

Linguistics is study about language. Language always changes and develops either internally or externally. They can examine historically and sociolinguistically. Language change is often brought about by contact between speakers of different languages or dialects, rather than by variation internal to a given speech community. Such changes are said to be due to external causes. Internal language change is occurs the behavior of speakers in their everyday lives to adjust to each other, and followed by a tendency to innovate in groups of people who are already familiar, then followed by other changes in sequence, which ultimately makes a language different each other, although originally derived from a single language family. It is grammar, phonology, phrase sequences, and sentence with gender function. The language change is from speaker in their life every day. The change will followed by other changes. External language external and development is caused by the contact of a language with other languages, where humans as social beings who have been 
cultured either interconnected or inter-ethnic nations in the world in a country. Humans need to communicate with other. They have many purposes in interaction with others. In this case language can change and develop.

\section{REFERENCES}

Aitchison, Jean. (2001). Language change: Progress or decay? 3rd edition. Cambridge: University Press.

Algeo, John. (2010).'The Origins and Development of English Language "USA:Wadsword

Bauer, Laurie (1994). Watching English change. An introduction to the study of linguistic change in standard Englishes in the twentieth century.London: Longman.

Bauer, Lauire.(2007).”The Linguistic students ' handbook” Edinburgh: Ediburgh University Press.

Brown H. Douglas.(2007). "Principal of language learning and teaching”, fifth Edition" Sans Fransisco State University : longman.

Campbell, Lyle (1998). Historical linguistics. An introduction. Edinburgh: University Press.

Campbell, Lyle. (2002)."The History of Linguistics." Blackwell Publishing Online

Crowley, Terry. (1998 [1992]). An introduction to historical linguistics. 2nd edition. Auckland: Oxford University Press.

Fennell, Barbara. (2001). A history of English. A sociolinguistic approach. Oxford:

Blackwell.

Harris, Alice C. and Lyle Campbell. (1995). Historical syntax in cross-linguistic perspective. Cambridge: University Press.

Hickey, Raymond. (2003). (ed.) Motives for language change. Cambridge: University Press.

Holmes, Janet. (1995). "An Introduction To Sociolinguistic" London and New York: Longman.

Seassure. De Ferdinand. (1959).Course in General Linguistics. New York: the philosophical Library,inc.

Ihalainen, Ossi. (1994). 'The dialects of England since 1776', in Burchfield (ed.), pp. 197274.

Kemenade, Ans van and Nigel Vincent (eds) (1997). Parameters of morphosyntactic change. Cambridge: University Press. 
Kenstowicz, Michael and Charles Kisseberth. (1979). Generative phonology. Description and theory. New York: Academic Press.

King, Robert. (1969). Historical linguistics and generative grammar. Englewood Cliffs, NJ: Prentice Hall.

Koutsoudas, A. (ed.) (1976). The application and ordering of grammatical rules. The Hague: Mouton.

Labov, William. (1981). 'Resolving the Neogrammarian controversy', Language 57: 267308.

Lahiri, Aditi (ed.) (2000). Analogy, levelling, markedness. Principles of change in phonology and morphology. Berlin: Mouton de Gruyter.

McMahon, April. (1994). Understanding language change. Cambridge: University Press.

Milroy, James. (1992). Linguistic variation and change. Oxford: Blackwell.

Newmeyer, Frederick J. (1998). Language form and language function. Cambridge, Mass.: MIT Press.

Pintzuk, Susan, George, Tsoulas and Anthony Warner (eds) (2001). Diachronic syntax. Models and mechanisms. Oxford: University Press.

Roberts, Ian. (1993). Verbs and Diachronic Syntax. Dordrecht: Kluwer.

Saussure, Ferdinand De (1959). Course in general Linguistics. New York: Philosophical Library.

Trask, Robert Lawrence. (1996). Historical linguistics. London: Arnold.

Willey, Norbert. (n.d.).Inner Speech as a language : A Saussurean Inquiryll Journal compilation (C) The Executive Management Committee/Blackwell Publishing Ltd. UK :Blackwell Publishing, Oxford. 